\title{
Incidence and causes of cancellations of elective operation on the intended day of surgery at a tertiary referral academic medical center in Ethiopia
}

Melaku Desta ${ }^{1 * \dagger}$, Addissu Manaye $^{2 \dagger}$, Abiot Tefera $^{2}$, Atalay Worku$^{2}$, Alemitu Wale$^{2}$, Alemlanchi Mebrat $^{2}$ and Negesso Gobena ${ }^{3}$

\begin{abstract}
Background: Elective surgical case cancellation refers to any elective surgical case that is the list on the day prior to surgery but not operated upon as scheduled. Case cancellation has a major cause of psychological trauma to patients and their families. Despite little is known in Ethiopia. Therefore, this study aimed to assess incidence and reasons of cancellations of elective operation on the intended day of surgery at tertiary referral academic medical center in Ethiopia.
\end{abstract}

Methods: A prospective hospital-based cross-sectional study design was conducted in a tertiary referral academic medical center in Ethiopia among 146 participants. A self-administered questionnaire with an observatory checklist was used for collecting data from the anesthetist, nurse, and surgeons.

Result: In this study, 462 patients were scheduled for elective surgical operations. Among those, nearly almost one-third 146 (31.6\%) of the operations were cancelled and 316 (68.4\%) patients were operated on their planned date. The most common reason for cancellation were surgeon related (35.8\%), patient related (28.7\%), management related (21.2\%) and anesthesia related factors (14. 4\%). The cancellation was mainly due to improper scheduling (20.5\%\%), unavailability of surgeons (8.9\%), unavailability of oxygen and blood (8\%) and equipment (5.5\%). Orthopedic (28.8\%) and general surgery (17.1\%) were the commonest cancelled cases.

Conclusion: The cancellation rate in our academic medical center remains high. Improper scheduling, unavailability of surgeons, medical illness, and unavailability of operating room equipment were the commonest reason for the cancellation of elective operation. Most cancellations were preventable. For this, proper preoperative assessment, proper scheduling, fulfilling necessary operating room equipment's and cross-matched blood by the hospital and other stakeholders, early clear communication with operating room team like surgeons was recommended.

Keywords: Cancellation, Elective surgery, Operating theatre, Ethiopia

\footnotetext{
* Correspondence: melakd2018@gmail.com

${ }^{\dagger}$ Melaku Desta and Addissu Manaye contributed equally to this work.

${ }^{1}$ College of Health Science, Department of midwifery, Debre Markos

University, PO. Box: 269, Debre Markos, Ethiopia

Full list of author information is available at the end of the article
}

(c) The Author(s). 2018 Open Access This article is distributed under the terms of the Creative Commons Attribution 4.0 International License (http://creativecommons.org/licenses/by/4.0/), which permits unrestricted use, distribution, and reproduction in any medium, provided you give appropriate credit to the original author(s) and the source, provide a link to the Creative Commons license, and indicate if changes were made. The Creative Commons Public Domain Dedication waiver (http://creativecommons.org/publicdomain/zero/1.0/) applies to the data made available in this article, unless otherwise stated. 


\section{Back ground}

Cancellation of elective operation on the intended day of surgery (DOS) is considered when a patient's name has appeared on the list for surgical operations but the operation was not done on the intended scheduled date [1]. DOS cancellations are a world-wide problem, ranging from $0.37-28 \%$ in developed [2-9] and from 11 to $44 \%$ in developing countries [10-14]. It can be avoidable and non-avoidable [15] and avoidable cancellations were the commonest [4, 16, 17].

Cancellation of elective operation decrease the over-all efficiency of the operating rooms(ORs), reduces utilization of OR time and waste resources [18], subsequently endup with high economic burden for the patients and hospitals associated with extended hospital stay and repeated pre-operative preparations [12, 16, 19-21]. Hence, OR generates the highest costs and the largest source of revenues for the hospitals [22]. It affects surgeon productivity and staff morale and also causes psychological trauma or distress for the patients and as well the families [20, 23].

There are different reasons of cancellation of elective surgery that varies from one hospital to another [24]. The range of reasons given include inadequate pre-op assessment and preparation [24-27], management related factors [13] or infrastructural limitations [12, 17], lack of operating room time $[6,28]$, and unavailability of hospital beds [3], patient-related factors [2, 4, 15], surgery related factors (surgeon related issues, improper scheduling [29] and Anesthesia related factors [30].

The most common reason of those cancellations was preventable [16].Despite most cancellations are avoidable and many improvements done for patient quality of care, cancellation of elective surgery is high in Ethiopia [29]. For this, an efficiency of the operating room theatre needs to be permanently and universally improved through addressing of information and reduction of cancellation of elective surgical procedures. However; the study is scarce in Ethiopia in the study area of interest. Therefore, this study was aimed to assess incidence and causes of cancellation of elective operation on the intended day of surgery at a tertiary referral academic medical center. The finding of this study will assist us in making to enhance efficiency and minimize wastage of already limited hospital resources and manpower, policymakers or planners to set their target with feasible interventions in the study area, as a baseline for further studies and might be a means of achieving the Sustainable Development Goals (SDGs).

\section{Methods}

\section{Study design and setting}

A prospective Hospital-based cross-sectional study was conducted in Hawassa university comprehensive specialized hospital, which is a tertiary referral academic medical center found in Hawassa town, one of the regional city in Ethiopia (it is the capital city of SNNPR) located at about $276 \mathrm{~km}$ from Addis Ababa. The hospital was built around 1996E.C and it serves as a regional referral hospital for a long period of time and now it becomes a comprehensive specialized hospital one year back.

The hospital has four major wards with their perspective OPD and also minor wards with over 400 beds and provides the high quality of patient care in a broad range of services to over 90, 200 outpatients, 18,116 hospitalized patients and 1092 emergency cases annually. The hospital has one main operation theatre, which has six rooms. These rooms are used for general surgery, orthopedic surgery, gynecologic surgery, urologic\& neurology and plastic surgery for both inpatient and outpatient. It was conducted from March 1-20, 2018.

\section{Study participants and sampling procedure}

All patients who admitted to the tertiary referral medical center for elective surgical procedures from March 130, 2018 were the source population. All patients who were scheduled to undergo routine elective surgical operation, but due to some reasons they could not have their surgery done were included and patients scheduled in a minor operating room for minor surgery, which does not have preoperative assessment sheet and emergency cases were excluded. The interview was started by selecting a random sample.

\section{Variables and measurement}

The dependent variable of the study was the cancellation of operation and the independent variables included were age, sex and ASA class, the type of operation canceled and reasons for cancellation. Cancellation of operation was defined as any elective operation that was either scheduled on the final theatre list for that day or was subsequently added to the list, and that was not performed on that day. The reasons for cancellation were categorized as hospital-related, surgeon-related, and patient-related and anesthetist related factors.

\section{Data collection technique, quality control}

A structured questionnaire was adapted from a validated and modified individual patient questionnaire and other related literature. Data on the canceled operations were obtained from the daily operating theatre list and documented in a special form. A pre-tested was done on $5 \%$ of the study subjects on other nearby health facility and training for 3 days was given. The causes for cancellation were provided by either the surgeon or the resident and prospectively recorded into the computerized database. The assigned OR staff confirmed the cancellation reason and added additional explanation if necessary by calling patients or through direct inquiry of clerical and clinical 
staff the following day. A questionnaire was prepared in English and translated into the local language and finally to English. Five Anesthesia students were collecting the data and one senior staff was recruited as supervisors. The data were checked on the daily basis for completeness and consistency.

\section{Data processing and analysis}

The data were checked, cleared, entered and analysised by using SPSS version (20.0). Descriptive and basic analytical statistics were used to summarize the data. Data were presented in the form of proportions, frequency tables and using bar graph. Means and standard deviation The analysis was done by reporting of STROBE statement checklist [31].

\section{Ethical considerations}

Ethical clearance and permission were obtained from Hawassa University, College of Medicine and Health Science Institutional review board and permission was secured from medical center director. Informed consent was obtained and confidentiality was ensured.

\section{Results}

\section{Sociodemographic demographic characteristics}

A total 462 elective surgical cases were scheduled for operation during the study period. The mean age of the participant was $26.7 \pm 4.37$ (SD) years and a majority of the participants were in the age group 21-30 years. From the study $316(68.4 \%)$ were operated on the intended day of surgery and $146(31.6 \%)$ were cancelled. From the cancelled cases $83(56.8 \%)$ were male and $61(43.2 \%)$ were female. Male to female ratio was 1.31:1. Male have a high rate of cancellation than female (Table 1).

\section{Causes of cancellation of elective operation}

The most frequent causes for elective case cancellation were surgeon-related factors, which accounts for 51 cases (35.8\%) followed by patiently-related reasons, (30\%) [Fig. 1]. Regarding, the surgeon related reasons, scheduling an emergency procedure $(11.6 \%)$ followed by over scheduling of elective cases (10.9\%) and unavailability of the surgeon (10.3\%) were the commonest reason of cancellation of elective surgery.

The highest frequent patient-related reasons for elective case cancellation were patients who have acute and chronic medical illness (11.6\%) and the leading reason is patient on medication for the treatment of this illness. Hypertension (35.3\%), diabetes mellitus (23.5\%), Ischemic heart diseases (17.6\%), urinary tract infections and other illnesses each account, (11.8\%) were the commonest illness. Administrative-related cause of cancellation of elective cases is primarily by lack of oxygen and blood (8\%) (Table 2).
Table 1 Sociodemographic characteristics of cancelled cases ( $n$ $=146$ ) at a tertiary referral academic medical center in Ethiopia, 2018

\begin{tabular}{llll}
\hline Variable & Category & Frequency & Percent \\
\hline Age & less than 10 & 25 & 17.1 \\
& $11-20$ & 21 & 14.4 \\
& $21-30$ & 34 & 23.3 \\
& $31-40$ & 29 & 19.9 \\
& $41-50$ & 17 & 11.6 \\
& $51-60$ & 12 & 8.2 \\
Sex & $61-70$ & 6 & 4.1 \\
& greater than 71 & 2 & 1.4 \\
ASA Class & Male & 83 & 56.8 \\
& Female & 63 & 43.2 \\
& ASAC-I & 87 & 59.6 \\
& ASA C III and above & 6 & 36.3 \\
\hline ASA America & 53 & 4.1 \\
\hline
\end{tabular}

ASA American Society of Anesthesia

\section{Cases cancelled among elective operations in each department}

Orthopedic was the department with the high rate of elective surgical cases scheduled 109 cases (23.6\%)from the total schedule and has high cancellation rate from the other department 42 cases (28.8\%) followed by general surgery which accounts 26 cases (17.1\%). The least cancellation rate was observed from maxillofacial department1 cases (0.6\%) [Fig. 2].

\section{Discussion}

Cancellation of elective surgical operations in hospitals is a significant problem with many undesirable consequences. Cancellations are a major drain on health resources, increases theatre costs, decrease patient satisfaction, wasted operating room time and decrease efficiency. An efficient surgical service should have a low rate of cancellation $[12,16,20]$.

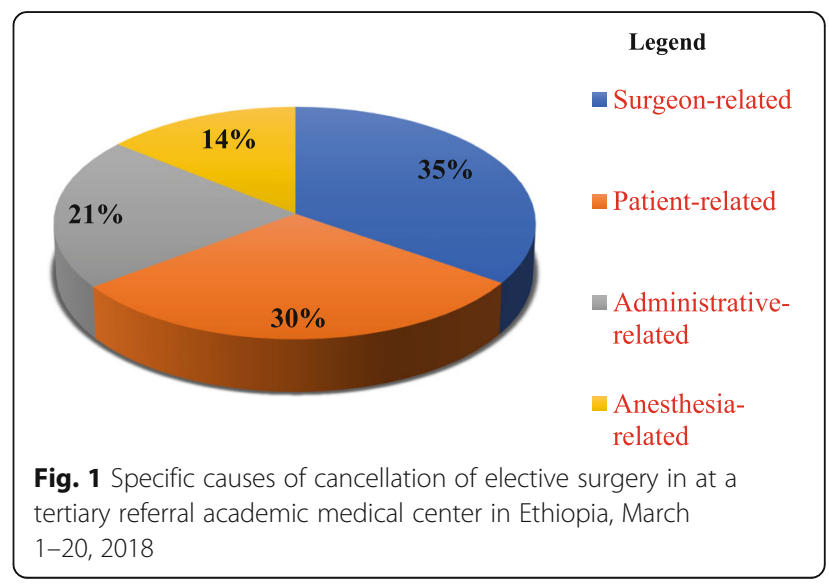


Table 2 Reasons of cancellation of elective surgery at a tertiary referral academic medical center in Ethiopia, 2018

\begin{tabular}{|c|c|c|}
\hline Reason of cancellation & Category & Frequency (\%) \\
\hline \multirow[t]{6}{*}{ Patient-related } & Refusal to surgery & $6(4.1)$ \\
\hline & patient on medication & $10(6.8)$ \\
\hline & Acute and chronic medical illness & 17(11.6) \\
\hline & patient not fasting & $7(4.8)$ \\
\hline & patient not paid & $4(2)$ \\
\hline & failure to arrive & $6(4.1)$ \\
\hline \multirow[t]{5}{*}{ Surgeon-related } & surgeon unavailability & 15(10.3) \\
\hline & diagnosis change & $5(3.4)$ \\
\hline & patient require other surgical workup & $9(6.2)$ \\
\hline & emergency scheduling & 17(11.6) \\
\hline & over scheduling of elective surgery & 16(10.9) \\
\hline \multirow[t]{4}{*}{ Administrative- related } & no availability of or equipment & $8(5.5)$ \\
\hline & delayed laboratory test & $6(4.1)$ \\
\hline & Lack of oxygen and blood & $12(8.0)$ \\
\hline & Unavailable of bed & $8(5.5)$ \\
\hline \multirow[t]{4}{*}{ Anesthesia -related } & patient unfit for anesthesia & $10(6.8)$ \\
\hline & Abnormal lab result & $5(3.4)$ \\
\hline & Unavailable equipment & $3(2.1)$ \\
\hline & Difficult intubation & $4(2.7)$ \\
\hline
\end{tabular}

The study revealed that about $31.6 \%$ of the elective surgical case was canceled, indicates preoperative system was inefficient. The result of the study is in line with studies done in India, 30.3\% [32] and Burkina Faso, $36.7 \%$ [13] and Nigeria, 28\% [1]. But, this finding is

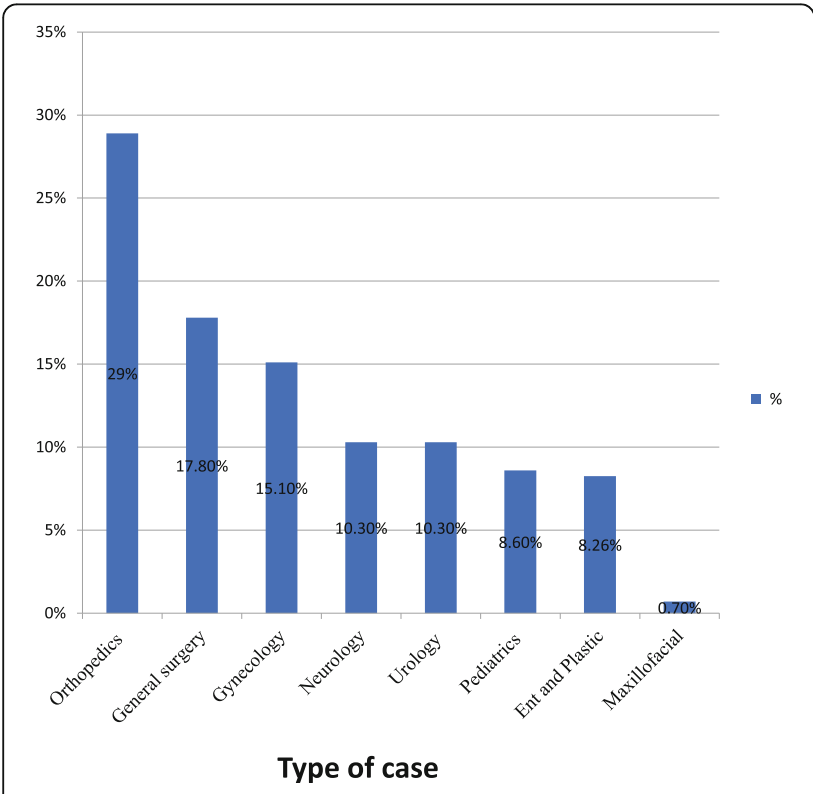

Fig. 2 Cases cancelled among elective surgery in each department at a tertiary referral academic medical center in Ethiopia, March 1-20, 2018 higher than when compared to other studies done in America, 4.4\% [4], Brazil 6.8\% [9], German, 12.7\% [33], Wales,7.6 [6], Tanzania, 21\% [12], New delhi,17.6\% [28], Sudan, 20.2\% [11], and Jimma University, 23\% [29]. This discrepancy might be due to the fact that in sociodemographic characteristics, sample size, study area, and methodological difference. Beyond this the operation theatre of this hospital being on innovation, lack of operating room equipment's and bed, unavailability of surgeon, and is the largest university specialized hospital at the regional level, results in higher case flow and referral cases, results decreasing operating room time and giving priority for emergency referral cases subsequently end up increased the number of cancelled cases.

21-30 years old age group were the highest canceled age groups $(23.3 \%)$ followed by $31-40$ years old group (19.9\%) canceled groups and less frequent cancellation were over the age of seventy (1.4\%) and in Spain cancellations [34] were more common in patients aged 010 years $(13 \%)$ followed by those aged $21-30$ years $(9 \%)$. Cancellations were less frequent in older age groups $(5 \%$ among 71-80 years and 6\% among 61-70 years [16]. But in Sudan [11], the highest canceled group was 6170 years old $31.1 \%$ followed by $51-60$ years old group $25.4 \%$ [18]. The difference might be due to those age groups; aged 0-10 and older age groups might be more likely assessed preoperatively before the day of surgery and given priority for them. 
Surgeon-related factors were the most common cause for cancellation of elective surgical cases in the hospital, which accounted for $51(35.8 \%)$ of cases. The commonest reason of surgeon related factor was scheduling of emergency surgery (11.6\%), scheduling of elective surgery (10.9\%) unavailability of a surgeon (10.3\%) and change of diagnosis is the least cause. This is supported by a study done in Spain [34], Hong Kong [6] and India [32], Burkina Faso [13] and Jima university [29], surgeon-related factors due unavailable operating time and unavailability of surgeons or inappropriate scheduling were the leading reason of elective surgical case cancellation. This is might be due to the fact that unavailability of surgeon and scheduling of emergency surgery is known the case for postponed the elective case on the day of surgery. Over scheduling of elective surgery might be more likely result in lack of available operating room time, results in cancellation of an elective case on the day of surgery.

This study revealed that patient-related factors were another common reason for the cancellation of elective surgical cases accounted (30\%) of canceled cases. This study is similar to other studies done in Brazil [9], India [32] and Burkina Faso [13], patient-related factors were the common cause for cancellation. Cancellation of the case caused by patient related factor was mainly due to acute and chronic medical illness and being on medication. This might have explained due to that those patients who haven't stop medications prior to the day of surgery according to the illness might affect the surgical procedure and action of the anesthetic agent.

Furthermore, administration related reason accounts for $21.2 \%$ for cancellation, the commonest were failed to prepare cross-matched blood $12(8 \%)$ followed by OR material shortage and bed unavailability 8(5.5\%). The finding is similar with compared to studies done at china [6], Saudi Arabia [35] and Sudan [11]. It is not surprisingly if the operating time is not fulfilling necessary equipment it delays operating room time and without cross-matched blood, difficult to do surgery. Hence, there might be bleeding, end up severe postoperative anemia and shock result cancellation of an elective surgical case.

Moreover, the study showed that orthopedic cases (28.7\%) followed by general surgery (17.8\%) and gynecology surgery (15.1\%) was the commonest and maxillofacial $(0.6 \%)$ was the least cancelled cases. This finding is supported by other similar studies conducted in Hong Kong [6], Saudi Arabia [35], orthopedics account, 33.9\%) and in Finland [36], 31.8\% orthopedics cases was the commonest canceled elective surgical procedure. This might be due to the fact that high rate of trauma and road traffic accident in the study area leads to giving priority for emergency orthopedic cases to maintain ongoing blood loss. Beyond this, it might have explained due to the fact that lack of cross-matched blood results in high rate of cancellation. Hence, orthopedic, gynecology, and general surgeries are the invasive procedure, which is more likely at risk of excessive bleeding.

This study can't make causal relationship (difficult to know which precede the exposure or outcome hence it is cross-sectional descriptive study and less likely to generalize to the general population hence it is a health facility based. In addition to this, there might be a recall bias, and being a self reported study might not give the exact figure of the cause of cancellation.

\section{Conclusions}

The rate of cancellation in this medical care center remains high. This study showed that the majority of cancellations were deemed avoidable and hospital related. Improper scheduling, unavailability of surgeons, acute and chronic medical illness and unavailability of operating room equipment were the commonest reason for the cancellation of an elective surgical case.

Cancellation of elective surgery can be prevented by simple steps and minimized if the patients with medical problems were detected early and referred for an anesthetic assessment soon after they are scheduled for surgery. Proper scheduling, provide adequate information for the scheduled patient, fulfilling necessary operating room equipment's including cross-matched blood by hospital administrators and other stakeholders, clear communication with operating room team especially surgeons to be available on their schedule, and improve operating theater efficiency was recommended to reduce avoidable cancellation.

\section{Abbreviations}

ASA: American Society of Anesthesiology; DOS: Day of Surgery; OPD: Outpatient Department; ORs: Operating Rooms; SDGs: Sustainable Development Goals; SNNPR: South nation nationality people representative; SPSS: Statistical package for the social science

Acknowledgements

Authors are thankful for Hawassa University and the study participants.

Availability of data and materials

The datasets used and analyzed during the current study are available from the corresponding author.

\section{Authors' contributions}

MD designed the study, reviewed and analsized the study, and wrote up the manuscript. AM, AT, AW, AM and NG were actively involved in design of the study, the supervision of the data collection, data analysis and preparation of the manuscript. All authors read and approved the final manuscript.

\section{Ethics approval and consent to participate}

The study protocol was reviewed and approved by Hawassa University Research Institutional review board. Official letter of cooperation was obtained from College of Medicine and Health Science to tertiary refferal medical center and permission was secured from the medical center clinical director. All study participants were informed that they have right not to participate in the study or stop the interview at any time they want if that 
was their choice. Written consent was obtained from all participants prior to interview. All information obtained in the study was stored confidential.

\section{Consent for publication}

Not applicable.

\section{Competing interests}

The authors declare that they have no competing interests.

\section{Publisher's Note}

Springer Nature remains neutral with regard to jurisdictional claims in published maps and institutional affiliations.

\section{Author details}

${ }^{1}$ College of Health Science, Department of midwifery, Debre Markos University, PO. Box: 269, Debre Markos, Ethiopia. ${ }^{2}$ College of medicine and Health Science, Department of Anesthesia, Hawassa University, Hawassa, Ethiopia. ${ }^{3}$ College of Medicine and Health Sciences, Lecturer and Senior Anesthetist, Hawassa University, Hawassa, Ethiopia.

\section{Received: 3 July 2018 Accepted: 20 August 2018}

Published online: 27 August 2018

\section{References}

1. Ebirim LN, Buowari DY, Ezike H. Causes of cancellation of elective surgical operations at a University Teaching Hospital. J Med Med Sci. 2012;3(5):297301.

2. Argo JL, Vick CC, Graham LA, Itani KM, Bishop MJ, Hawn MT. Elective surgical case cancellation in the Veterans Health Administration system: identifying areas for improvement. Am J Surg. 2009;198(600):6.

3. Schofield WN, Rubin GL, Piza M, Lai YY, Sindhusake D, Fearnside MR, et al. Cancellation of operations on the day of intended surgery at a major Australian referral hospital. Med J Aust. 2005;182(12):612-5.

4. Kaddoum R, Fadlallah R, Hitti E, El-Jardali F, El Eid G. Causes of cancellations on the day of surgery at a Tertiary Teaching Hospital. BMC Health Serv Res. 2016;16:259

5. Abeeleh MA, Tareef TM, Hani AB, Albsoul N, Samarah OQ, ElMohtaseb MS, et al. Reasons for operation cancellations at a teaching hospital: prioritizing areas of improvement. Ann Surg Treat Res. 2017;93(2):65-9.

6. Chiu CH, Lee A, Chui PT. Cancellation of elective operations on the day of intended surgery in a Hong Kong hospital: point prevalence and reasons. Hong Kong Med J. 2012;18(1):5-10.

7. Dhafar KO, Ulmalki MA, Felemban MA, Mahfouz ME, Baljoon MJ, Gazzaz ZJ, et al. Cancellation of operations in Saudi Arabian hospitals: Frequency, reasons and suggestions for improvements. Pak J Med Sci. 2015:31(5):1027-32.

8. Sung WC, Chou AH, Liao CC, Yang MW, Chang CJ. Operation cancellation at Chang Gung Memorial Hospital. Chang Gung Med J. 2010;33(5):568-75.

9. Santos GAAC, SCM B. Cancellation of elective surgeries in a Brazilian public hospital: reasons and estimated reduction. Rev Bras Enferm. 2017:70(3):535-42

10. Elrahman AA, Hamza AA, EL-Haj MA. Cancellation of Elective General Surgical Operations at the Day of Intended Surgery Global Journal of HUMAN-SOCIAL SCIENCE: I Surgeries and Cardiovascular System 2014;14(3).

11. Mutwali IM, Abbass AM, Elkheir IS, Arbab SS, Bur A, Geregandi T. Cancellation of elective surgical operations in a teaching hospital at Khartoum Bahri, Sudan. Sudan Med Monit. 2016:11(2):196.1.28.51.

12. Chalya PL, Gilyoma JM, Mabula JB, Simbila S, Ngayomela IH, Chandika AB, et al. Incidence, causes and pattern of cancellation of elective surgical operations in a university teaching hospital in the Lake Zone, Tanzania. Afr Health Sci. 2011;11(3):438-43.

13. Lankoandea M, Bonkoungoub P, Traorea S, Kaborea R, Ouangrec $E_{1}$ Pendeville $P$. Cancellation of elective surgical procedures in the university teaching hospital center Yalgado Ouedraogo in Burkina Faso: incidence, reasons and proposals for improvement. South Afr J Anaesth Analg. 2016; 22(5):140-4

14. Prin M, Eaton J, Mtalimanja O, Charles A. High Elective Surgery Cancellation Rate in Malawi Primarily Due to Infrastructural Limitations. World J Surg. 2018;42(6):1597-602
15. Mulira M, Smith MD, Moorman J. Factors Contributing To Elective Theatre Cancellations In The Department Of Surgery At Chbah. South Afr J Surg Suid-Afrikaanse tydskrif vir chirurgie. 2017;55(2):66-7.

16. Leslie RJ, Beiko D, van Vlymen J, Siemens DR. Day of surgery cancellation rates in urology: Identification of modifiable factors. Can Urol Assoc J. 2013; 7(5-6):167-73.

17. Yu K, Xie X, Luo L, Gong R. Contributing factors of elective surgical case cancellation: a retrospective cross-sectional study at a single-site hospital. BMC Surg. 2017;17(1):100.

18. Dexter F, Blake JT, Penning DH, Lubarsky DA. Calculating a potential increase in hospital margin for elective surgery by changing operating room time allocations or increasing nursing staffing to permit completion of more cases: a case study. Anesth Analg. 2002;94(1):138-42.

19. Mangan JL, Walsh C, Kernohan WG, Murphy JS, Mollan RA, McMillen R, et al. Total joint replacement: implication of cancelled operations for hospital costs and waiting list management. Qual Health Care. 1992;1(1):34-7.

20. Perroca MG, Jerico Mde C, Facundin SD. Surgery cancelling at a teaching hospital: implications for cost management. Rev Lat Am Enfermage. 2007; 15(10):18-24.

21. Van Klei WA, Moons KGM, Rutten CL, Schuurhuis A, Knape JTA, Kalkman CJ, et al. The effect of outpatient preoperative evaluation of hospital inpatients on cancellation of surgery and length of hospital stay. Anesth Analg. 2002; 94(3):644-9.

22. Association HFM. Achieving operating room efficiency through process integration. Healthc Financ Manage. 2003;57(3):suppl 1-7 following 112.

23. Tait AR, Voepellewis T, Munro HM, Gutstein HB, Reynolds PI. Cancellation of pediatric outpatient surgery: economic and emotional implications for patients and their families. J Clin Anesth. 1997:9(3):213-9.

24. Lee A, Kerridge RK, Chui PT, Chiu CH, Gin T. Perioperative Systems as a quality model of perioperative medicine and surgical care. Health Policy. 2011:102:214-22.

25. McKendrick DR, Cumming GP, Lee AJ. A 5-year observational study of cancellations in the operating room: Does the introduction of preoperative preparation have an impact? Saudi JAnaesth. 2014;8(Suppl 1):S8-s14.

26. Farasatkish R, Aghdaii N, Azarfarin R, Yazdanian F. Can preoperative anesthesia consultation clinic help to reduce operating room cancellation rate of cardiac surgery on the day of surgery? Middle East J Anaesthesiol. 2009;20(1):93-6.

27. Epstein $\mathrm{RH}$, Dexter F. Management implications for the perioperative surgical home related to inpatient case cancellations and add-on case scheduling on the day of surgery. Anesth Analg. 2015;121(1):206-18.

28. Kumar R, Gandhi R. Reasons for cancellation of operation on the day of intended surgery in a multidisciplinary 500 bedded hospital. J Anaesthesiol Clin Pharmaco. 2012:28:66-9.

29. Haile M, Desalegn N. Prospective Study of Proportions and Causes of Cancellation of Surgical Operations at Jimma University Teaching Hospital, Ethiopia. Int J Anesth Res. 2015;3(2):87-90.

30. Hussain AM, Khan FA. Anaesthetic reasons for cancellation of elective surgical inpatients on the day of surgery in a teaching hospital. J Pak Med Assoc. 2005;55(9):374-8.

31. Von Elm E, Altman D, Egger M, Pocock S, Gøtzsche PJV. The Strengthening the Reporting of Observational Studies in Epidemiology (STROBE) statement: guidelines for reporting observational studies. Bull World Health Organ. 2007;85:867-72

32. Garg R, Bhalotra AR, Bhadoria P, Gupta N, Anand R. Reasons for cancellation of cases on the day of surgery-a prospective study. Indian J Anaesth. 2009; 53(1):35-9.

33. Schuster M, Neumann C, Neumann K, Braun J, Geldner G, Martin J, et al. The effect of hospital size and surgical service on case cancellation in elective surgery: results from a prospective multicenter study. Anesth Analg. 2011; 113(3):578-85.

34. Arshad Z, Tariq M, Samson G, Sajjad A. Cancelled elective general surgical operations in ayub teaching hospital. J Ayub Med Coll Abbottabad. 2007; 19(3):66.

35. El-Dawlatly A, ATurkistani, Aldohayan A, Zubaidi A, Ahmed A. Reasons of Cancellation of Elective Surgery in A Teaching Hospital. Int J Anesthesiol. 2007;15:2

36. Laisi J, Tohmo H, Keränen U. Surgery Cancelation on the Day of Surgery in Same-Day Admission in a Finnish Hospital. Scand J Surg. 2013;102:3204-8. 